\title{
Lutowanie ceramiki AIN ze stopem FeNi42 za pośrednictwem powłoki metalizacyjnej osadzanej tarciowo
}

\author{
Brazing of AIN ceramics with FeNi42 alloy \\ through metallic coating deposited \\ by friction onto ceramic surface
}

\section{Streszczenie}

Złącza ceramiki z metalami bazują na wysokotemperaturowych, długotrwałych procesach próżniowych, głównie o charakterze dyfuzyjnym. Opisane w artykule badania są częścią pracy badawczej ukierunkowanej na opracowanie technologii tarciowego osadzania powłok metalizacyjnych na ceramice w celu ułatwionego spajania, w tym lutowania ceramiki z metalami. W celu uproszczenia procesu lutowania ceramiki z metalami na powierzchni ceramiki konstrukcyjnej wytwarzana jest cienka powłoka metaliczna ułatwiającą lutowanie z metalami z wykorzystaniem lutów nieaktywnych w osłonie gazów. W pracy zaprezentowano wstępne wyniki badań złączy lutowanych ceramiki AIN ze stopem FeNi42 uzyskanych za pośrednictwem tarciowo osadzanej powłoki metalizacyjnej.

Słowa kluczowe: lutowanie twarde; złącza ceramika-metal; ceramika AIN; metalizacja ceramiki

\begin{abstract}
Ceramics-metal joints usually are obtained in high-temperature and long-time vacuum processes where the mechanism for the creation of interface is based on the diffusion phenomena. The research has been reported at this article is the part of the bigger scientific project focused on friction metallization of ceramic surface. In order to simplify the process of brazing metals to the ceramics a thin metallic coating is deposited onto ceramics surface by friction surfacing. Due to the intermediate metallic coating brazing process of the ceramicmetal joints can be realized by inactive solder in atmosphere of inert shielding gas. The preliminary results of ceramic AIN with alloy FeNi42 brazing process obtained through friction-deposited coating have been reported.
\end{abstract}

Keywords: brazing; ceramics-metal joints; AIN ceramics; metallization

\section{Wstęp}

W nowoczesnym przemyśle złącza ceramiczno-metalowe znajdują szerokie zastosowanie i dotyczą coraz nowszych gatunków ceramiki w tym również AIN. Złącza metalowoceramiczne umożliwiają kojarzenie z natury odmiennych właściwości komponentów w określoną cechę wyrobu [1]. Metalizacja jest jednym ze sposobów ułatwiania uzyskania złącza ceramiczno-metalowego, a jej celem jest zmiana właściwości warstwy wierzchniej ceramiki umożliwiającej zwilżenie metalem z natury nieaktywnym w stosunku do ceramiki. Powłoka metalizacyjna w następnym etapie pośredniczy w uzyskaniu złącza pomiędzy litym materiałem ceramicznym i metalowym, np. na drodze lutowania twardego lub zgrzewania [2]. Metalizacja powierzchni materiałów ceramicznych stanowi kluczowy etap technologicznego wytwarzania pośrednich połczeń ceramika-metal. W przypadku par składających się z materiałów ceramicznych i metalowych, w których występuję wysoki stopień powinowactwa chemicznego składników łączonych materiałów, możliwe jest bezpośrednie spajanie ceramiki z metalami, lecz takie podejście powoduje ograniczoną możliwością komponowania złączy [3,4]. Niniejszy artykuł porusza specjalny przypadek lutowania złącza ceramiki AIN ze stopem FeNi42 za pośrednictwem tytanowej powłoki osadzanej tarciowo na ceramice, a następnie pokrytej niklem w procesie galwanicznym. Koncepcja pracy polega na opracowaniu technologii łączenia ceramiki, bez angażowania wielogodzinnych, wysokotemperaturowych procesów próżniowych opartych na zjawiskach dyfuzyjnych.

\section{Powłoka metalizacyjna - metoda wytwarzania i charakterystyka}

Powłoka metalizacyjna została osadzona na powierzchni ceramiki metodą tarciową. Czoło robocze narzędzia tytanowego ( $\mathrm{Ti}$ - grade 2) o średnicy zewnętrznej $9 \mathrm{~mm}$ z otworem w osi o średnicy $3 \mathrm{~mm}$ trąc o powierzchnię płyty ceramiki AIN o grubości $6 \mathrm{~mm}$ (rys. 1) osadza cienką powłokę, na sku-

Mgr inż. Michał Hudycz; dr hab. inż. Tomasz Chmielewski, prof. PW - Politechnika Warszawska.

Autor korespondencyjny/Corresponding author: mhudycz@wp.pl 
tek przenoszenia metalu z czoła narzędzia na powierzchnię ceramiki. Celem procesu było uzyskanie na powierzchni ceramiki równomiernej powłoki metalizacyjnej z tytanu. Tytan wybrano z powodu tego wysokiego powinowactwa chemicznego do składników metalizowanej ceramiki. Proces metalizacji opisano w pracach $[5,6]$, natomiast wpływ warunków dostarczania energii do powstających złączy ma-

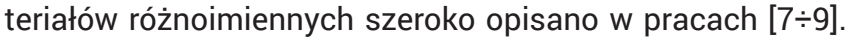
Proces tarciowego metalizowania składa się z wstępnej fazy nagrzewania tarciem pod naciskiem 13,4 MPa tytanowej kształtki, która obraca w głowicy z prędkością 2550 obr/ min., a po ustabilizowaniu się warunków, narzędzie wykonuje ruch postępowy względem powierzchni ceramiki.

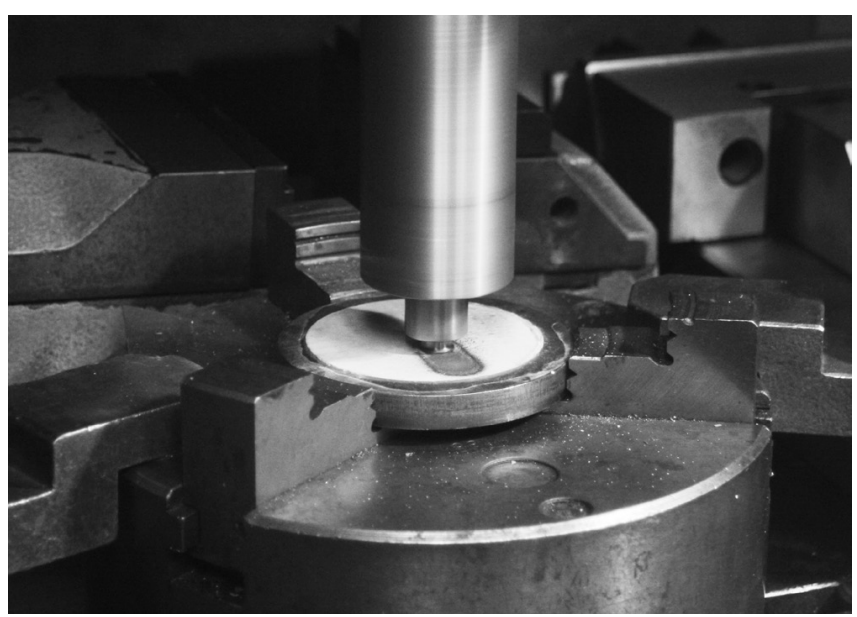

Rys. 1. Narzędzie w pracy oraz widok powstającej powłoki

Fig. 1. The friction tool during operation and a view of the emerging coating

Na rysunku 2 przedstawiono widok powłoki metalizacyjnej wykonanej kilkoma równoległymi przejściami narzędzia z zakładką zapewniającą ciągłość powłoki. Budowę fazową, mikrostrukturę oraz inne właściwości powłoki opisano szczegółowo w pracach [5,6], ze względu na trudności ze zwilżeniem tytanowej powłoki została pokryta galwanicznie niklem o grubości $5 \div 7 \mu \mathrm{m}$.

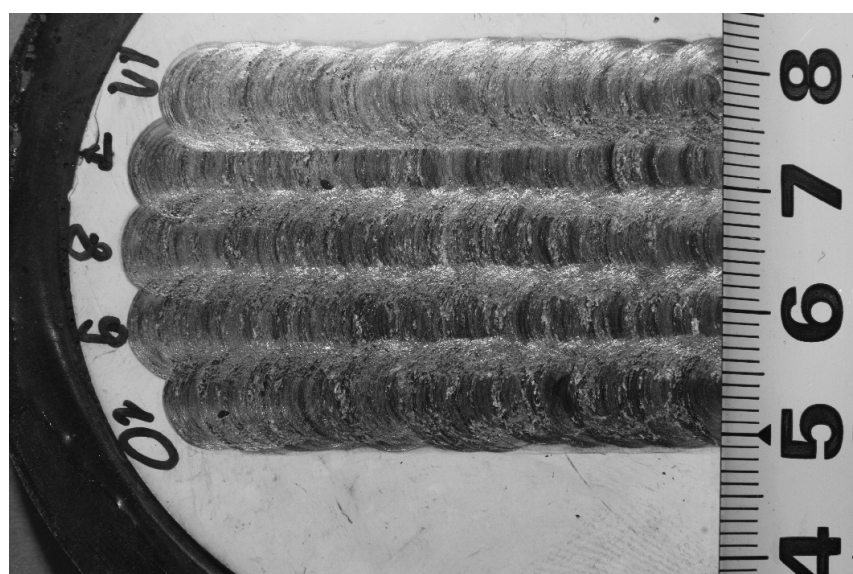

Rys. 2. Powłoka metalizacyjna składająca się z kilku ściegów prostych wykonanych z zakładką

Fig. 2. Metallization coating consists of few passes with overlapping

\section{Lutowanie złączy ceramika-metal}

Proces lutowania przeprowadzono w otwartej od góry przepłukiwanej argonem komorze pieca indukcyjnego z transformatorem generatora indukcyjnego MFG5, przepływ argonu wynosił ok $14 \mathrm{l} / \mathrm{min}$. Źródłem ciepła dla lutowanych próbek był grzany indukcyjnie szablon grafitowy (rys. 3) o wymiarach $\emptyset 33 \times 30 \mathrm{~mm}$ i grubości ścianek ok. $10 \mathrm{~mm}$. W jednym procesie lutowano trzy próbki. Elementy ceramiczne $z$ metalizowaną powierzchnią miały wymiary $8 \times 9 \times 4,5$ mm, lut eutektyczny AgCu28 (Ag 272 wg ENISO 17672) w formie folii o grubości $0,15 \mathrm{~mm}$ i powierzchni $8 \times 9 \mathrm{~mm}$. Próbki ceramiczne ustawiono w dnie otworu szablonu, na metalizowaną górną powierzchnię położono lut, a na wierzch osiowosymetrycznie krążek stopu FeNi42 o średnicy $11 \mathrm{~mm}$ i grubości $5 \mathrm{~mm}$.

W osi szablonu pomiędzy próbkami lutowanymi umiejscowiono próbkę referencyjną bez lutu z otworem $\varnothing 1,5 \mathrm{~mm}$ w krążku metalowym w którym umieszczono termoelement $\mathrm{NiCr} / \mathrm{NiAl}$. Nagrzewanie przebiegało z prędkością $25^{\circ} \mathrm{C} / \mathrm{min}$, zastosowano przystanek temperaturowy na poziomie $720^{\circ} \mathrm{C}$ o czasie $10 \mathrm{~min}, \mathrm{w}$ celu wyrównania temperatury lutowanych elementów. Temperatura lutowania wynosiła $860{ }^{\circ} \mathrm{C}$, a czas lutowania 1 minuta.

Warunki stygnięcia po lutowaniu:

- $860 \div 760^{\circ} \mathrm{C}-200^{\circ} \mathrm{C} / \mathrm{min}$

- $760 \div 300^{\circ} \mathrm{C}-30^{\circ} \mathrm{C} / \mathrm{min}$

- $300 \div 20^{\circ} \mathrm{C}$ - swobodne stygnięcie przy wyłączonym grzaniu

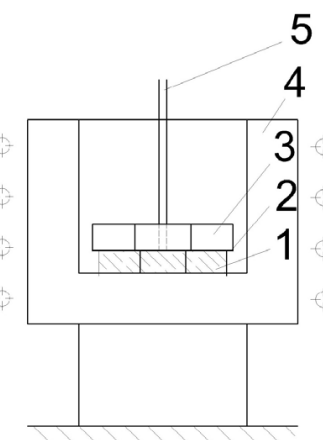

6 Rys. 3. Szkic szablonu do lutowania: 1) metalizowana próbka ceramiczna ceramika AIN, 2) lut $A g C u 28,3)$ krążek FeNi42, 4) szablon grafitowy, 5) termoelement NiCr-NiAl, 6) cewka indukcyjna

Fig. 3. A sketch of brazing template: 1) metallized sample of AIN ceramic, 2) AgCu28 solder, 3) FeNi42 disk, 4) graphite template 5) thermocouple $\mathrm{NiCr}$ $\mathrm{NiAl}, 6)$ induction coil

\section{Mikrostruktura złączy lutowanych}

Złącza lutowane preparowano do badań metalograficznych wykonując cięcie piłą diamentową prostopadle do połączenia, następnie inkludowano w twardej żywicy epoksydowej i szlifowano tarczą diamentową do uzyskania płaszczyzny przekroju złącza. W kolejnym etapie polerowano zgład przy pomocy pasty diamentowej. Zgłady fotografowano bez trawienia. Na rysunku 4 pokazano mikrostrukturę złącza lutowanego AIN-FeNi42 przy powiększeniu 100 razy. Profil menisku widocznego na zdjęciu wskazuje na porównywalną zwilżalność łączonych komponentów.

Na rysunku 5 pokazano mikrostrukturę złącza lutowanego AIN-FeNi42 z powiększeniem x500, dzięki czemu można wyraźnie zaobserwować obecność dwóch warstw pośrednich. Sumaryczna grubość połączenia (lut + powłoki pośrednie) wynosi około $30 \mu \mathrm{m}$. Pierwsza tytanowa o grubości w zakresie od 3 do $5 \mu \mathrm{m}$ osadzona tarciowo. Druga warstwa to elektrochemicznie osadzony nikiel o grubości w zakresie od 6 do $8 \mu \mathrm{m}$. Nikiel zastosowano na skutek znacznych trudności z powtarzalnym zwilżaniem lutem AgCu28 powierzchni tytanu $[10,11]$ w tym przypadku osadzanego tarciowo. Dodatkowe pokrycie powłoki tarciowej niklem pełni jednocześnie funkcję plastycznego kompensatora naprężeń. 


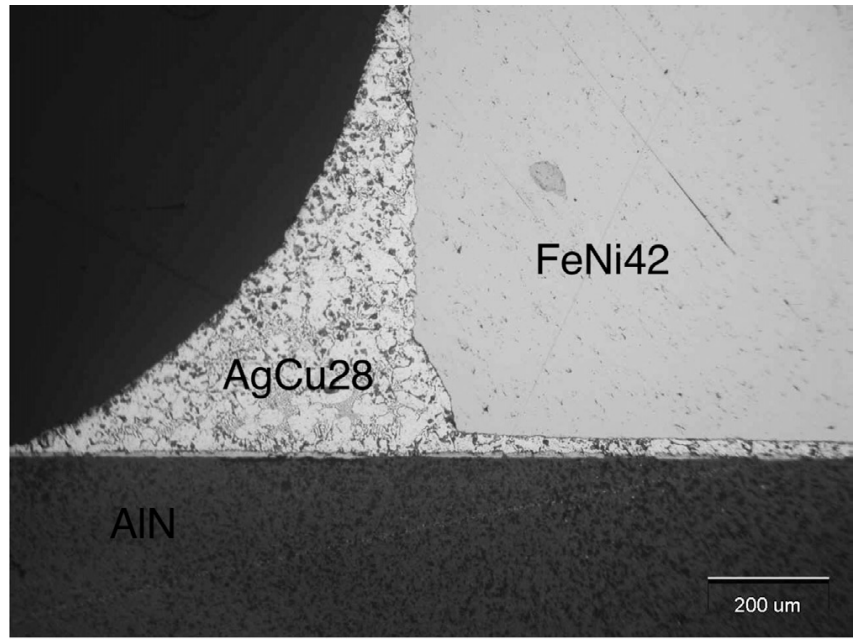

Rys. 4. Mikrostruktura złącza lutowanego AlN-FeNi42

Fig. 4. Microstructure of AIN-FeNi42 brazed joint

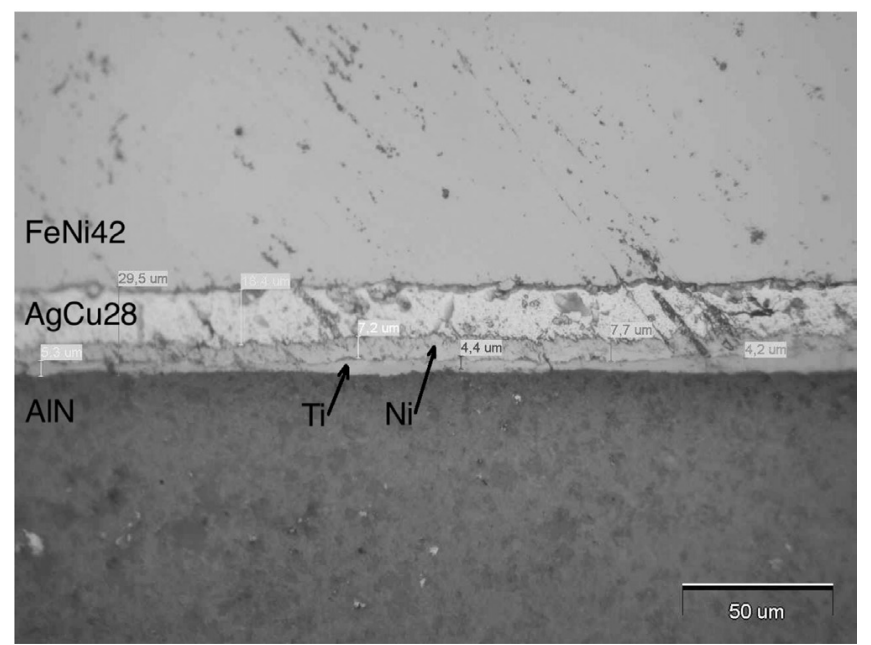

Rys. 5. Mikrostruktura złącza lutowanego AlN-FeNi42 z widocznymi warstwami pośrednimi - Ti osadzany tarciowo, Ni osadzany galwanicznie

Fig. 5. Microstructure of brazed AIN-FeNi42 joint, with visible interlayers, Ti deposited by friction and Ni galvanically deposited

\section{Podsumowanie i wnioski}

Przeprowadzono próby lutowania ceramiki AIN po metalizacji tarciowej ze stopem FeNi42 lutem srebrno-miedzianym AgCu28. Lutowanie prowadzono w piecu indukcyjnym w atmosferze argonu. Powłokę metalizacyjną uprzednio naniesiono metodą tarciową, a następnie pokryto galwanicznie niklem. Dodatkową powłokę niklową zastosowano w następstwie trudności ze zwilżeniem lutem AgCu28 tarciowo osadzonego Ti. Uzyskane złącza lutowne o grubości około 30 um, charakteryzują się ciągłością i brakiem wyraźnych niedoskonałości. W kolejnym etapie prac badawczych przeprowadzone zostaną testy wytrzymałości uzyskanych złączy. Przeprowadzony i przedstawiony w niniejszym artykule eksperyment wskazuje na możliwość uzyskania trwałych złączy ceramiczno-metalowych wykonanych bez stosowania kilkudziesięciogodzinnych, próżniowych procesów termicznych o charakterze dyfuzyjnym.

\section{Literatura}

[1] Chmielewski T.: Wykorzystanie energii kinetycznej tarcia i fali detonacyjnej do metalizacji ceramiki, Prace Naukowe PW, Seria Mechanika, Zeszyt 232, 2012, s.1-155.

[2] K. Pietrzak, D. Kaliński, M. Chmielewski, T. Chmielewski, W. Wlosiński, K. Choręgiewicz: Processing of intermetallics with Al203 or steel joints obtained by friction welding technique, Proc. 12th Conference of the European Ceramic Society - ECerS XII, Stockholm (2011).

[3] Włosiński W., Chmielewski T., Kucharczyk M.: Spajanie tarciowe stopów NiAl i FeAl ze stalą węglową St3S, Przegląd Spawalnictwa, vol. 76, nr 1, s. 6-12. 2004.

[4] Włosiński W., Chmielewski T., Grabowska A.: Warunki spajania tarciowego i struktura złączy Al2O3-Al i Al2O3-Cu, Przegląd Spawalnictwa, vol. 75, nr 12, s.1-5. 2003.

[5] Hudycz M.,Winiarski M., Chmielewski T.: Tarciowe metalizowanie ceramiki AIN tytanem, Przegląd Spawalnictwa, vol. 87, nr 10, s. 31-35, 2015.

[6] Hudycz M., Chmielewski T., Winiarski M., Golański D.: Właściwości tytanowej powłoki metalizacyjnej osadzanej tarciowo na ceramice Al, Prze- gląd Spawalnictwa, vol. 88, nr 5, s. 29-35, 2016

[7] Chmielewski T., Golański D., Włosiński W., Zimmerman J.: Utilizing the energy of kinetic friction for the metallization of ceramics. Bulletin of the Polish Academy of Sciences Technical Sciences, vol. 63, nr 1, s. 201-207, 2015

[8] Rogalski G., Fydrych D., Walczak W.: Wpływ cyklu cieplnego na właściwości zgrzewanych wybuchowo złączy stal-aluminium, Przegląd Spawalnictwa, vol. 85, nr 6, s. 60-54, 2013.

[9] Rogalski G., Fydrych, D., Walczak W.: Zastosowanie zgrzewania wybuchowego do wytwarzania kompozytów metalowych z osnową ceramiczną. Przegląd Spawalnictwa, vol. 85, nr 6, s. 54-59, 2013.

[10] Mirski Z., Różański M.: Lutowanie dyfuzyjne tytanu i jego stopu na osnowie fazy TiAl (y). Inżynieria Materiałowa, nr 2/2010, s. 161-166.

[11] Mirski Z., Różański M., Winiowski A.: Lutowanie dyfuzyjne tytanu z użyciem przekładek z miedzi i niklu, Przegląd Spawalnictwa, vol. 84, nr 10, s.15-18, 2012 